\title{
Psychiatry and terrorism: exploring the unacceptable
}

\author{
Donatella Marazziti*
}

Dipartimento di Medicina Clinica e Sperimentale, Section of Psychiatry, University of Pisa, Pisa, Italy

Sometimes humans have short memories or, at least, they tend to forget bad events. Probably this is also promoted by the constant flow of information and news bombarding us every second, so that it is difficult to extract what should be retained and not forgotten. Let us consider what happened after the terrorist attacks in Paris (France), San Bernardino (USA), and Bamako (Mali), just to mention some of the most recent and relevant in terms of number of victims. They were round the clock news broadcasts; interviews with witnesses, family members of victims or injured individuals, or common people; several debates with experts of different disciplines; funeral ceremonies; public speeches from authorities condemning the brutal acts and promoting specific actions to repress future attacks, but what then? After some weeks and other terroristic, albeit not so spectacular, attacks, the media interest on terrorism seems to be waning. The result is that in the last few weeks, more emphasis was given to attacks that would have been prevented in different European capitals (although probably there might be a specific intent to reassure people worldwide during the Christmas holidays).

As a psychiatrist, I feel a sense of discomfort and disappointment when watching debates on TV or reading newspaper articles trying to provide some explanation of the possible reasons for terrorism. Indeed, if one considers the kind of experts approaching this problem, it is evident that is handled primarily by sociologists, politicians, economists, service persons, theologians, and, quite seldom, at least in my country, by some psychologists. The weight of sociological and cultural factors is with no doubt important in the genesis of terrorism. The impact of economic crisis on young generations all over the world is similarly fundamental, as it may foster frustration and uncertainty when facing or projecting the future. ${ }^{1,2}$ The combination of such elements with loss and/or refusal of traditional values in second- and third-generation immigrants may trigger a sense of emptiness and isolation,

* Address for correspondence: Donatella Marazziti, MD, Dipartimento di Medicina Clinica e Sperimentale, Section of Psychiatry, University of Pisa, Via Roma, 67, 56100 Pisa, Italy.

(Email: dmarazzi@psico.med.unipi.it) which can be easily manipulated by some evil leaders and directed toward novel and "higher" ideals within a "religious" framework. 3,4 The concomitant use of CNS stimulants, such as Captagon or others, may perhaps lead to abnormal behaviors of destruction and self-destruction in vulnerable subjects.

The exploration of how this may happen, of what are the mechanisms transforming young individuals into terrorists and suicide bombers, in my opinion, are some of the most challenging questions that psychiatrists, psychologists, and neuroscientists should try to debate and to investigate. ${ }^{5,6}$ The impression is that sometimes psychiatrists neglect, underestimate, or are somehow reluctant to explore such abnormal behaviors, as if there were a sort of worry that they would be charged with reductionism if approaching these phenomena. We should recall that criminologists are primarily psychiatrists and psychologists who obviously have the possibility of visiting the criminals, while there are just a few suicide bombers surviving or arrested. Unfortunately, to the best of my knowledge, no information has been shared with the scientific community, with the exception of that provided by the studies of Ariel Merari, who had the opportunity to administer structured interviews and tests to several surviving Palestinian suicide bombers and drew some possible psychological profiles. ${ }^{7}$ Even if it is true that eventual psychiatrist explanations might represent just a minor part of the problem, in any case they should not be disregarded. In fact, the incidence of sociopathy and antisocial personality disorder is about $1-2 \%$ of the general population, ${ }^{8}$ and it is probably not enough to explain the extreme violence of the latest terrorist attacks. However, I believe that the sociopathy model might represent a starting point for trying to make some hypotheses on possible psycho(patho)logical profiles and features of terrorists. Sociopathic individuals are generally defined as those who lack empathy, regret, or guilt for their actions; who feel little or no pity; or who manifest a cold and calculated aggression, without alterations of their higher cognitive processes. Some features of present-day terrorists resemble those of sociopathic individuals or antisocial personality, in particular lack of empathy and of moral sense. ${ }^{8-10}$ 
It has been also reported that sociopathic subjects may show blunted alterations in cardiac frequency, in skin conductance, in respiratory activity, or in responses of the autonomic nervous system, when looking at frightening or unpleasant pictures or when facing images of the suffering of others. ${ }^{11-14}$ Empathy consists of the capacity to understand or feel what another is feeling or experiencing, and to share another individual's emotions or feelings. ${ }^{15}$ Empathy encompasses different emotional states, including caring for other people and wishing to help them. Empathy belongs to the so-called "moral or social-moral emotions," which are linked to the interests and wellbeing of a society or group rather than of single individuals. It is possible that empathy and other feelings, such as unwillingness to harm others, a sense of justice, and the so-called "theory of mind," a term that describes one's capacity to understand the thoughts, feelings, and emotions of others, which developed because of its utility in the survival of humans as it promotes cooperation. ${ }^{16,17}$ Empathy, the theory of mind, and morality, processes that are strictly related, have been hypothesized to be regulated by brain circuits, involving the right ventromedial prefrontal cortex (VMPFC) and the adjacent orbitofrontal and ventrolateral cortex (OFC/VL), the amygdala, and the dorsolateral prefrontal cortex (DLPFC), with all their connections to other limbic, hypothalamic, and brainstem areas. ${ }^{18-21}$ Mirror neurons, which are activated by when an action is carried out by an individual, or when he/she observes that action being performed by another, might also be involved in social feelings, although at the moment they have been described only in motor areas. The ability of the human brain to self-activate when the emotions of others are perceived, as expressed through facial mimicry, gestures, and tone of voice, as well as the ability to immediately decode this perception in "visceromotor" terms, enables every individual to act according to so-called "empathic participation." 22,23 It is generally believed that empathic participation might be at the basis of all social behaviors. However, it should be mentioned that these are only hypotheses, as until now mirror neurons have been found only in motor areas.

Terrorists, like sociopaths, seem to lack totally these kinds of abilities and feelings, ${ }^{24}$ as it is clearly evident after viewing the shocking and appalling images of smiling perpetrators of brutal executions; they show a chilling coldness, a calculated indifference, and a cruelty with shameless self-celebration. Their lack of humanity is amplified by a skillful use of modern technologies.

In order to try to understand these behaviors, obviously, we, as psychiatrists, psychologists, and neuroscientists, must overcome the strong repugnance and disgust that they evoke inside us, and instead focus on sharp, "technical," rather than moralistic, analyses, with the clear premise that understanding what is morally unacceptable does not in any way justify it. ${ }^{25}$ Understanding the unacceptable is, in fact, intended to prevent or to limit the contagion it may exert on young people in the present-day desert of values. ${ }^{5}$ Therefore, in my opinion, one of the possibilities might be to explore more and more in-depth the brain mechanisms that underlie moral emotions, such as empathy, theory of mind, innate morality, sense of guilt, gratitude, and pity, which all have great social value and have promoted the progress of our species. It is also mandatory to elucidate which factors might promote their correct development or their rescue. This last aim undoubtedly would involve a global (re)shaping and rethinking of social and economic politics, as well as educational programs in children and adolescents, especially those being raised in risky environments.

\section{Disclosures}

The author does not have anything to disclose.

\section{REFERENCES:}

1. Atran S. Genesis of suicide terrorism. Science. 2003; 299(5612): 1534-1539.

2. Lankford A. Précis of the myth of martyrdom: what really drives suicide bombers, rampage shooters, and other self-destructive killers. Behav Brain Sci. 2014; 37(4): 351-362.

3. Blain M. Social science and the biopolitics of terrorism. Sociology Compass. $2015 ;$ 9(3): 161-179.

4. Sela Y, Shackelford TK. The myth of the myth of martyrdom. Behav Brain Sci. 2014; 37(4): 376377.

5. Marazziti D. Is there a role for psychiatry in deepening our understanding of the "suicide bomber"? Int J Psychiatry Clin Pract. 2007; 11(2): 87-89.

6. Burnham G. Suicide attacks-the rationale and consequences. Lancet. 2011; 378(9794): 855-857.

7. Merari A. Driven to Death: Psychological and Social Aspects of Suicide Terrorism. New York: Oxford Press; 2010.

8. Blair RJ. Applying a cognitive neuroscience perspective to the disorder of psychopathy. Dev Psychopathol. 2005; 17(3): 865-891.

9. Raine A, Yang Y. Neural foundations to moral reasoning and antisocial behavior. Soc Cogn Affect Neurosci. 2006; 1(3): 203-213.

10. Marazziti D, Baroni S, Landi P, Ceresoli D, Dell'osso L. The neurobiology of moral sense: facts or hypotheses? Ann Gen Psychiatry. 2013; 12(1): 6-15.

11. Levenston GK, Patrick CJ, Bradley MM, Lang PJ. The psychopath as observer: emotion and attention in picture processing. J Abnorm Psychol. 2000; 109(3): 373-385.

12. Raine A, Buchsbaum M, LaCasse L. Brain abnormalities in murderers indicated by positron emission tomography. Biol Psychiatry. 1997; 42(6): 495-508.

13. Markowitsch HJ. Neuroscience and crime. Neurocase. 2008; 14(1): 1-6.

14. Intrator J, Hare R, Stritzke $\mathrm{P}$, et al. A brain imaging (single photon emission computerized tomography) study of semantic and affective processing in psychopaths. Biol Psychiatry. 1997; 42(2): 96-103.

15. Bellet PS, Maloney MJ. The importance of empathy as an interviewing skill in medicine. JAMA. 1991; 226(13): 1831-1832.

16. Wilson J. The Moral Sense. NewYork: Simon \& Schuster; 1993. 
17. Haidt J. The new synthesis in moral psychology. Science. 2007; 316(5827): 998-1002.

18. Heekeren HR, Wartenburger I, Schmidt H, Schwintowski HP, Villringer A. An fMRI study of simple ethical decision-making. Neuroreport. 2003; 14(9): 1215-1219.

19. Moll J, de Oliveira-Souza R, Eslinger PJ, et al. The neural correlates of moral sensitivity: a functional magnetic resonance imaging investigation of basic and moral emotions. J Neurosci. 2002; 22(7): 2730-2736.

20. Moll J, de Oliveira-Souza R, Eslinger PJ. Morals and the human brain: a working model. Neuroreport. 2003; 14(3): 299-305.

21. Decety J, Jackson PL. The functional architecture of human empathy. Behav Cogn Neurosci Rev. 2004; 3(2): 71-100.
22. Gallese V. Before and below 'theory of mind': embodied simulation and the neural correlates of social cognition. Philos Trans $R$ Soc Lond B Biol Sci. 2007; 362(1480): 659-669.

23. Oberman LM, Pineda JA, Ramachandran VS. The human mirror neuron system: a link between action observation and social skills. Soc Cogn Affect Neurosci. 2007; 2(1): 62-66.

24. Damasio AR, Tranel D, Damasio H. Individuals with sociopathic behavior caused by frontal damage fail to respond autonomically to social stimuli. Behav Brain Res. 1990; 41(2): 81-94.

25. Post JM, Ali F, Henderson SW, Shanfield S, Victoroff J, Weine S. The psychology of suicide terrorism. Psychiatry. 2009; 72(1): 13-31 